\title{
Experimental evaluation of the roles of habitat selection and interspecific competition in determining patterns of host use by two anemonefishes
}

\author{
Maya Srinivasan*, Geoffrey P. Jones, M. Julian Caley \\ School of Marine Biology and Aquaculture, James Cook University, Townsville, Queensland 4811, Australia
}

\begin{abstract}
We examined the roles of interspecific competition and habitat preference in determining the distribution of 2 anemonefish species, Premnas biaculeatus and Amphiprion melanopus, among the 2 morphs of the anemone Entacmaea quadricolour. This anemone species has a solitary morph which is usually occupied by a single pair of $P$. biaculeatus and a colonial morph which is usually occupied by large social groups of A. melanopus. The possibility that interspecific competition, and/or preference of adults of each species of fish for the anemone morph it usually occupies, determines this distribution was tested using aquarium based experiments. Adults of one species, A. melanopus, displayed a preference for the anemone morph it usually occupies in the field, but $P$. biaculeatus did not. Instead, $P$. biaculeatus pairs tended to associate closely, always occupying the same anemone regardless of the morph chosen. While interspecific competition limited fish abundance within anemones, competitive interactions could not explain the distribution of fish species among anemone morphs. That is, neither fish species displaced the other more often on the anemone morph it usually occupies in the field. While juvenile $P$. biaculeatus exhibit some preference for solitary morphs and $A$. melanopus appear to prefer colonial morphs, juvenile distributions cannot fully explain the distribution of adults. Instead, we suggest that adult distributions are explained by a combination of juvenile habitat preferences, adult-juvenile interactions and constraints imposed by the contrasting social systems of the 2 species.
\end{abstract}

KEY WORDS: Habitat selection - Interspecific competition - Distribution - Specialisation - Coral-reef fish Anemonefish Amphiprion melanopus - Premnas biaculeatus

\section{INTRODUCTION}

The role of interspecific competition in the partitioning of resources among species is a central tenet of ecological theory (MacArthur \& Levins 1964, 1967. Armstrong \& McGehee 1980, Connell 1980, 1983, Schoener 1983, 1985) and has been the subject of longstanding debate in the ecology of high diversity coralreef fish communities (e.g. Sale 1978, 1980, Smith 1978, Anderson et al. 1981, Sale \& Williams 1982, Doherty \& Williams 1988, Caley et al. 1996). Proponents of interspecific competition in these communities have highlighted the fine partitioning of resources as

•E-mail: maya.srinivasan@jcu edu.au evidence for the importance of competitive interactions (e.g. Smith \& Tyler 1972, Robertson \& Lassig 1980, Waldner \& Robertson 1980). However, subsequent workers in challenging the role of interspecific competition, stressed the high degree of resource overlap observed in many guilds of reef fishes (Sale 1978, Robertson 1984, Roberts 1985).

Recent experiments investigating the importance of competition in reef fish communities have produced mixed results. Despite often strong interspecific competition, a number of studies have failed to demonstrate any effect of 1 competing species on the growth and mortality of another (Doherty 1982, Robertson 1984, Roberts 1987, Jones 1988, 1991). However, a number of studies have shown that interspecific pat- 
terns of resource use can be influenced by competition (Ebersole 1985, Robertson \& Gaines 1986), and in 1 study a long-term effect of one species on the abundance of another competing species has been demonstrated (Robertson 1996). Therefore, although there has been considerable speculation that competition is important in the ecology of tropical reef fishes, it has not been widely demonstrated.

Instead, distinct patterns of habitat and resource use among species may be maintained by strong habitat preferences within species. The evolution of these preferences may or may not have involved competition in the past (Connell 1980), but would maintain differences in habitat use among species in the absence of any currently operating competitive processes provided the preferred habitat of each species provides a fitness advantage. Detailed studies of patterns of habitat use in coral-reef fishes have nearly always detected substantial differences among species, particularly at the time of settlement (Sale et al. 1984, Eckert 1985. Victor 1986, Ohman et al. 1998). Habitat-choice experiments have demonstrated that patterns of habitat use can be established by active choice between different kinds of reef substrata (Sale et al. 1980, 1984, Williams 1980, Ohman et al. 1998) and different depths (Eckert 1985, Williams 1980) by settling fishes. For most groups of reef fishes, however, the importance of habitat preferences in determining patterns of distribution and resource use is not well understood.

Anemonefishes have well-defined patterns of habitat use that vary interspecifically (Fautin \& Allen 1992). These species, therefore, provide an opportunity to evaluate the relative importance of interspecific competition and habitat selection in establishing patterns of resource use. Anemonefishes are obligate symbionts of anemones and, therefore, their abundance and distribution are limited by that of their hosts (Allen 1972, Dunn 1981) Host specificity varies among anemonefish species; some fish occupy a single host species, most occupy between 2 and 6 host species and 1 species, Amphiprion clarkii, occupies all 10 host species (Allen 1972, Dunn 1981). Patterns of host use by anemonefish species, however, are not always directly related to the relative abundances of their host species (Fautin 1985, 1986, Elliot 1992) and competition among species for preferred hosts is thought to be 1 factor influencing the distribution of anemonefishes among hosts (Mariscal 1972, Fautin 1985, 1986). Although they exhibit strong habitat selection at the time of settlement (Elliott et al. 1995), the degree to which this explains the distribution of adults is unknown.

Resource partitioning between 2 anemonefish species, Premnas biaculeatus and Amphiprion melanopus, is particularly well developed. Both fish species occupy the anemone species Entacmaea quadricolour. P. bi- aculeatus occupies this anemone exclusively, and, while A. melanopus has been reported to occupy 2 other anemone species (Allen 1972, Dunn 1981, Fautin \& Allen 1992), it usually occupies E. quadricolour. E. quadricolour has 2 distinct morphs: a large solitary morph (up to $30 \mathrm{~cm}$ oral disc diameter) and a colonial morph which consists of aggregations of many smaller, presumably clonal, anemones (Dunn 1981, Fautin 1986). The 2 anemonefish species appear to partition this anemone resource, with $P$. biaculeatus most often occurring in pairs in solitary anemones, and A. melanopus most often occurring in social groups of up to 20 individuals in colonial anemones (Ross 1978, Fautin 1986). The relative importance of habitat selection and interspecific competition in determining this pattern is unknown. It has been suggested that $E$. quadricolour is the 'most preferred' host anemone among anemonefish species as it hosts the largest number of these fish species (Fautin 1986). P. biaculeatus is restricted io E. quadricolour throughout its geographic range (Allen 1972, Fautin 1986) and is thought to be competitively dominant over other anemonefish species (Fautin 1986). However, while it is clear ihd intraspecific competition limits fish abundance within anemones (Fautin 1985, 1986, 1992), the role of interspecific competition in determining interspecific patterns of host use is less clear.

Here we attempt to elucidate the relative roles of habitat preference and interspecific competition in determining patterns of host use between Amphiprion melanopus and Premnas biaculeatus. Although it has been commonly observed that $P$. biaculeatus usually occupies solitary Entacmaea quadricolour and A. melanopus usually occupies colonial E. quadricolour, the extent to which this host resource is segregated between these 2 fish species has not been quantified. Therefore, we began by determining the extent of resource partitioning of E. quadricolour morphs by $P$. biaculeatus and $A$. melanopus using visual surveys. Then, using experiments, we determined the relative importance of habitat selection and interspecific competition in determining this pattern of distribution. In addition, we tested whether there was competitive dominance of one anemonefish species over the other and whether this dominance was habitat specific. That is, was one species competitively dominant in both habitat types, or was there a reversal of competitive dominance depending on the anemone morph occupied?

\section{MATERIALS AND METHODS}

Distribution of Premnas biaculeatus and Amphiprion melanopus between Entacmaea quadricolour morphs. The distribution of $P$. biaculeatus and A. melanopus between solitary and colonial morphs of $E$. quadri- 
Colour was estimated using visual surveys at Lizard Island $\left(14^{\circ} 40^{\prime} \mathrm{S}, 145^{\circ} 28^{\prime} \mathrm{E}\right)$, Great Barrier Reef, during February and April, 1997 , and in Kimbe Bay $\left(5^{\circ} 30^{\prime} \mathrm{S}\right.$, $150^{\circ} 05^{\prime} \mathrm{E}$ ), Papua New Guinea, during May, 1997. Four $100 \times 10 \mathrm{~m}$ transects were surveyed at each of the 12 sites around Lizard Island and 8 sites in Kimbe Bay. The proportions of adults and juveniles $(<30 \mathrm{~mm}$ total length [TL]) of each species occupying each E. quadricolour morph at the 2 locations were estimated. Because the 2 morphs of E. quadricolour are thought to have different depth distributions (Fautin 1986) and such a difference might influence habitat choices of anemonefishes, the depths of solitary and colonial morphs were also recorded.

Habitat-choice experiment. In order to quantify preferences of the 2 anemonefish species for Entacmaea quadricolour morphs, a habitat-choice experiment was conducted in aquaria at the Lizard Island Research Station in April 1997. This experiment involved placing 2 fish of each species (separately) in aquaria with solitary and colonial morphs at either side. Pairs of Premnas biaculeatus and groups of Amphiprion melanopus were collected and kept in tanks for at least $48 \mathrm{~h}$ to allow them to acclimatise to captivity before being used in experimental trials. All fish used in this experiment were $>30 \mathrm{~mm}$ TL. On average, fish were kept in captivity for $7 \mathrm{~d}$. Three specimens of solitary E. quadricolour and 3 sets of colonial E. quadricolour were collected and allowed to attach to concrete blocks in circular (diameter $=1150 \mathrm{~mm}$, approx. water depth $=600 \mathrm{~mm}$ ), fibre-glass tanks. Three of these tanks were established with a solitary anemone on one side and 5 or 6 colonial anemones (roughly matching the surface area of the solitary anemone) on the other side. Water flowed into each tank from a pipe placed on one side of the tank (equal distance from each of the anemone morphs) and out through a pipe at the bottom of the tank on the opposite side. Fish were introduced to the centre of the experimental tank through a PVC pipe attached to the bottom of an inverted bucket. Evenly spaced around the wall of the bucket were four mesh-covered holes. Two of these holes faced the anemones. Two fish (either a pair of $P$. biaculeatus or the 2 largest individuals from an $A$. melanopus social group) were introduced to the bucket at approximately 18:00 h and left for $15 \mathrm{~min}$ to acclimatise, after which the bucket was removed. The positions of the fish (i.e. occupying solitary or colonial anemones) were recorded after $1 \mathrm{~h}$ and again the following morning at approximately 06:30 h. Because the minimum size of social groups of anemonefishes in the field is 2, pairs of fish were used throughout these experiments. We assumed that behaviours exhibited by members of a pair were independent. Ten trials were carried out for each of the 2 species; pairs of fish were used in only 1 trial each.
The patterns of association between these 2 anemonefish species and the 2 anemone morphs could be the result of preferences of each species for each habitat or preferences for habitats occupied by conspecifics. If preference for a particular anemone morph is important in determining these patterns of association in the field, Premnas biaculeatus individuals would be expected to choose the solitary anemones and Amphiprion melanopus individuals would be expected to choose the colonial anemones more frequently than expected by chance. Otherwise, if habitats are selected based on the presence of conspecifics individuals should associate irrespective of the anemone morph selected. We tested for preference for anemone morphs by comparing the frequency with which each species selected each morph to that expected if no preference was exhibited. We then tested the possibility that habitats are selected based on the presence of conspecific individuals by comparing the frequency with which individuals occupied anemone morphs as pairs regardless of which morph they occupied. Binomial probabilities of obtaining results as extreme as those observed were estimated. These probabilities depend on 3 parameters: the number of trials, the probability of a success in each trial, and the number of successes. When examining habitat preference, the choice by an individual of the anemone morph most frequently occupied by that species in the field was scored as a success. The number of trials was 20 (i.e. we treated each individual in the 10 pairs tested as an independent trial) for each species, and the probability of a success, if fish chose habitats at random, was 0.5 . When examining whether habitats are selected based on the presence of conspecifics, 2 fish occupying the same anemone morph (regardless of the morph chosen) was scored as a success. In this case, the number of trials was 10 for each species and the probability of a success, if the fish occupied habitats at random, was 0.5 .

Interspecific competition experiment. The potential for interspecific competition between Premnas biaculeatus and Amphiprion melanopus on 1 or both morphs of Entacmaea quadricolour to determine the distribution of these fish species among morphs was examined at Lizard Island using a competition experiment. This experiment tested for the presence of competition between these species for anemones, whether 1 fish species is competitively dominant in both anemone morphs, or whether each species is dominant on the anemone morph it usually occupies in the field. The experiment was carried out using aquaria of the same design as those used in the habitat-choice experiment described above. Four aquaria were used in this experiment: 2 with a solitary anemone in each and 2 with 5 or 6 colonial anemones (roughly matching the 
surface area of the solitary anemone) arranged in a group. No colonial anemone was more than $5 \mathrm{~cm}$ away from another. In each tank, a concrete block was placed on the opposite side of the tank to the anemone(s) to provide shelter for fish displaced from the anemone(s). Water flowed across the tank between the anemone(s) and the concrete block (as described above). The fish used were the same as those used in the habitat-choice experiment. A pair of Premnas biaculeatus and a pair of Amphiprion melanopus were placed together near each of the 2 anemone morphs. The presence of interspecific competition in this experiment was indicated by at least 1 individual of 1 species expelling both individuals of the other species. As individuals may be expelled from anemones due to intraspecific competition, trials in which each species was placed separately on each type of anemone at the same total density (i.e. 2 pairs) were also conducted.

Ten trials were conducted for each of these 6 treatments (the 2 interspecific and 4 intraspecific treatments) with 4 trials run concurrently and randomised among the 6 treatments. In each trial, 2 pairs of fish were removed from their holding tanks using a hand net and placed into 2 PVC pipes (150 mm diameter, $800 \mathrm{~mm}$ long) set up within the experimental aquarium on either side of the test anemone(s). All fish were measured (standard length) prior to the experiment and in each trial fish pairs were matched for size as closely as possible. In the interspecific treatments, 2 Amphiprion melanopus individuals that roughly matched the size of the Premnas biaculeatus pair were used. In the intraspecific treatments the 2 largest $A$. melanopus individuals in each social group were used. Fish were allowed to acclimatise for $15 \mathrm{~min}$, after which the PVC pipes were slowly and concurrently removed, leaving the 2 pairs of fish at opposite sides of the anemone(s). The fish were observed for an hour to determine which individuals occupied the anemone(s), as well as how aggressive the fish were to one another. Fish that occupied the anemone(s) were scored as 'winners' and those that did not occupy the anemone(s) were scored as 'losers'. The level of aggression was estimated by recording the number of aggressive interactions or attacks in a 5 min period after the fish had started to interact. In each trial, 'attack distance', or the minimum distance that losers could approach the anemone(s) without being attacked by winners, was estimated. Shorter attack distances were interpreted to indicate less aggression than long attack distances. Preliminary observations indicated that several behaviours reported in previous studies characterised antagonistic or submissive interactions. Antagonistic behaviours included fighting (where 2 fish would each hold a pectoral fin of the other in its mouth), chasing and nudging, and appeasement behaviour which involved shaking of the body and substratum-biting (Mariscal 1972, Moyer \& Bell 1976). Observations of these behaviours were made in order to further assess the level of aggression in each treatment.

Due to a shortage of available fish, pairs were used more than once, but each pair was not used in the same treatment more than once. Pairs that were used more than once were distributed among different treatments to minimise the bias that could be caused by any particular pair behaving differently from the rest. On average, each pair of fish was used in 4 trials.

The presence of inter- or intraspecific competition was tested in each of the 6 treatments using the same form of frequency analysis outlined above. In this case, there were 16 possible outcomes in each trial, ranging from 0 to 4 fish occupying anemone(s). Because anemonefish are always associated with anemones in the field, in these analyses we did not include the possible outcome that no fish would occupy the anemone(s) presented. Therefore, the number of possible outcomes used in these analyses was 15 . Under each hypothesis examined, a number of possible outcomes were scored as successes. For example, in the 2 interspecific treatments (i.e. both solitary and colonial morphs), trials in which 1 or 2 fish of 1 species expelled the 2 fish of the other species were scored as successes. There were 6 possible ways in which this outcome could be obtained by a random assortment of fish among anemones. Therefore, the probability of a success in this case was 6/15. The number of trials was 10 . For the 4 intraspecific treatments, the outcomes that we scored as successes were based on the observed associations of each of the 2 species in the field (see results below). For example, Premnas biaculeatus is usually found in pairs, therefore, trials (for both solitary and colonial anemone morphs) in which one pair of fish expelled the other were scored as successes. In this case, the probability of a success was $4 / 15$. Amphiprion melanopus usually occupy colonial anemones in large groups. In colonial anemones, trials in which all 4 fish occupied the anemone were scored as successes, with the probability of a success being $1 / 15$. In solitary anemones, trials in which only 1 fish occupied the anemone were scored as successes, with the probability of a success being $4 / 15$.

The sizes of winning and losing fish were compared using paired $t$-tests. For the Premnas biaculeatus intraspecific treatments (solitary and colonial treatments combined), the sizes of female winners and losers, and male winners and losers, were compared. For Amphiprion melanopus, the size of the largest winner was compared to the size of the largest loser. For the mixed-species (interspecific) treatments, the trials where $P$. biaculeatus won and those where A. melanopus won were separated. In each case, the sizes of 
(a)

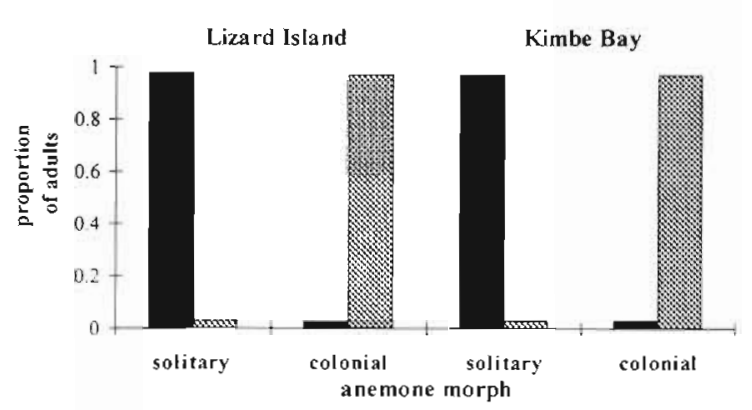

(b)

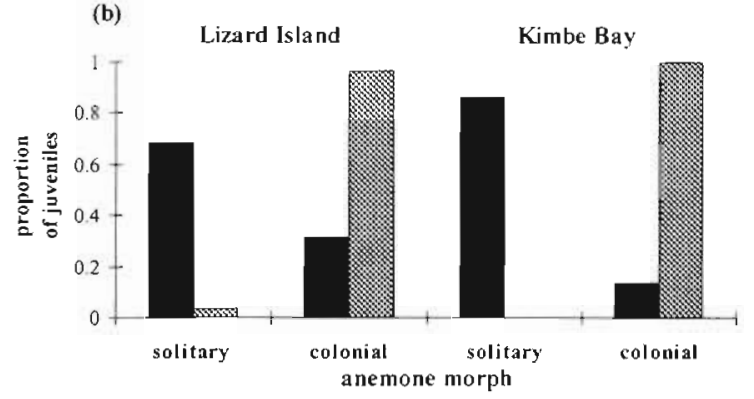

Fig. 1. Distribution of Premnas biaculeatus and Amphiprion melanopus among Entacmaea quadricolour morphs at Lizard Island, Great Barrier Reef, and Kimbe Bay, Papua New Guinea, shown as the proportion of (a) adults and (b) juve. niles of each species occupying each of the 2 morphs

the largest winner and the largest loser were compared.

Frequency of attacks (number of attacks in 5 min) and attack distance in the interspecific and intraspecific treatments were compared using separate 1-way ANOVAs with planned contrasts. Solitary and colonial treatments were combined, and interspecific trials were divided into those where Premnas biaculeatus won and those where Amphiprion melanopus won. The planned contrasts were between the 2 interspecific cases (i.e. where $P$. biaculeatus won vs where $A$. melanopus won), between the 2 intraspecific treatments (i.e. intraspecific P. biaculeatus vs intraspecific A. melanopus), and between the 2 intraspecific treatments and the interspecific treatment.

\section{RESULTS}

\section{Distribution of Premnas biaculeatus and Amphiprion melanopus between Entacmaea quadricolour morphs}

At both Lizard Island and Kimbe Bay, Premnas biaculeatus adults occupied solitary Entacmaea quadricolour $97 \%$ of the time (Lizard Island: $n=198$ fish, Kimbe Bay: $\mathrm{n}=125$ fish, Fig. 1a). In contrast, Amphi- prion melanopus adults occupied colonial E. quadricolour $97 \%$ of the time (Lizard Island: $n=143$ fish, Kimbe Bay: $\mathrm{n}=32$ fish, Fig. 1a). Fourty-six percent of $P$. biaculeatus juveniles at Lizard Island ( $\mathrm{n}=26)$, and $14 \%$ at Kimbe Bay ( $\mathrm{n}=29$ ), occupied colonial $E$. quadricolour (Fig, 1b). Where juvenile P. biaculeatus occurred in colonial anemones they occupied peripheral anemones in a colonial cluster occupied by a group of $A$. melanopus. In the rare instances (Lizard lsland: 4 of 139 adults and 2 of 52 juveniles, Kimbe Bay: 1 of 31 adults) where $A$. melanopus occurred in solitary anemones, they occupied it as a single fish. Colonial $E$. quadricolour generally occurred in shallower water than solitary E. quadricolour at both locations (Fig. 2). At both locations, 80 to $90 \%$ of colonial E. quadricolour were shallower than $4 \mathrm{~m}$, and over $50 \%$ of solitary $E$. quadricolour were $4 \mathrm{~m}$ or deeper. There was less of a difference in depth distributions between the 2 morphs at Lizard lsland mainly due to most sites at Lizard Island being shallower than those in Kimbe Bay.

\section{Habitat-choice experiment}

Premnas biaculeatus did not exhibit a preference for solitary anemones (solitary morph chosen by 12 fish, colonial morph chosen by 8 fish, binomial probability
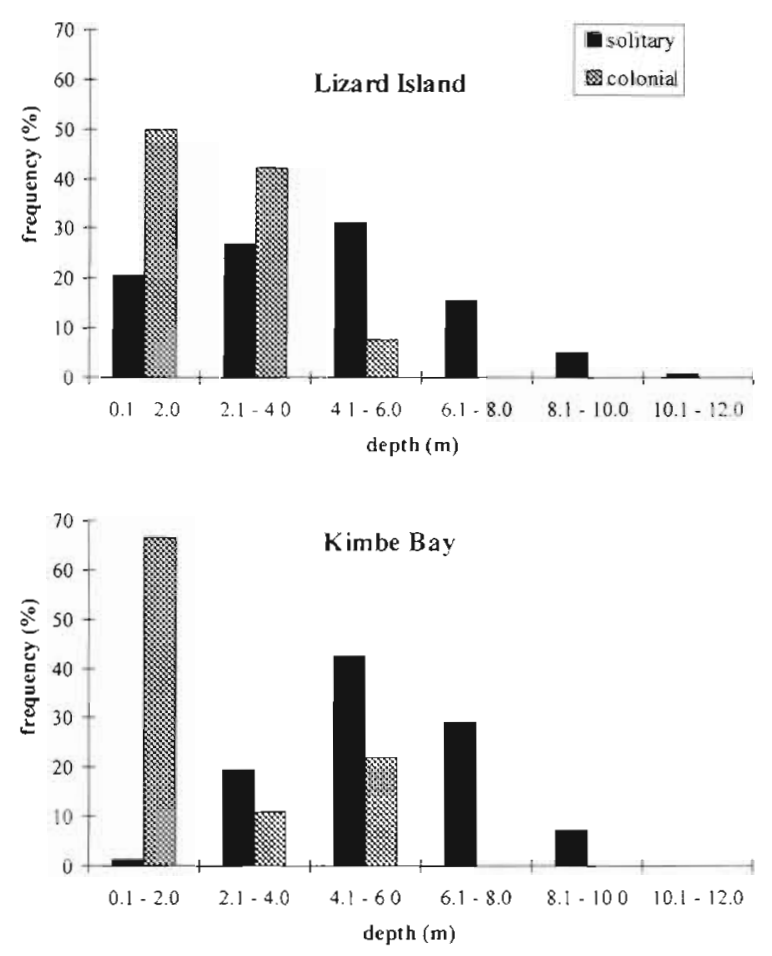

Fig. 2. Depth distributions of solitary and colonial Entacmaea quadricolour at Lizard Island, Great Barrier Reef, and Kimbe Bay, Papua New Guinea 


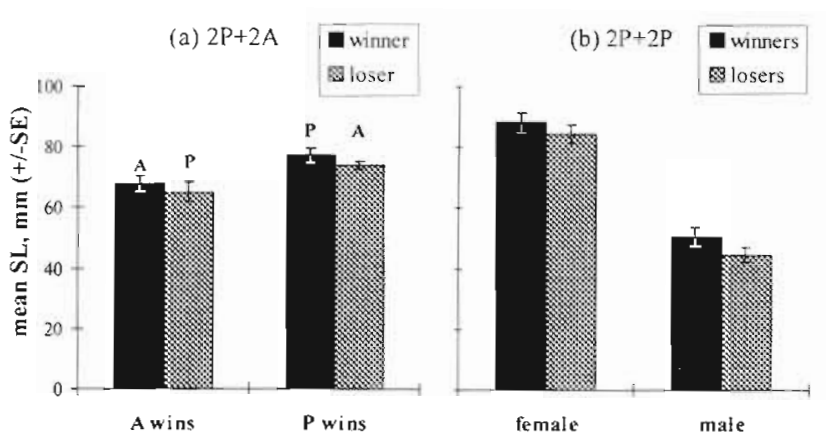

$p>0.120$ ), the morph it occupies most frequently in the field. In contrast, Amphiprion melanopus exhibited a preference for colonial anemones (solitary morph chosen by 6 fish, colonial morph chosen by 14 fish, binomial probability $\mathrm{p}<0.05$ ). P. biaculeatus individuals associated with one another in all 10 trials regardless of their choice of anemone morph (6 pairs chose solitary anemones and 4 pairs chose colonial morphs, binomial probability $\mathrm{p}<0.05$ ). A. melanopus individuals acted independently and always occupied anemones singly (binomial probability $\mathrm{p}<0.05$ ). When one $A$. melanopus individual (usually the larger of the two) occupied the solitary anemone, the other fish always occupied 1 or more of the colonial anemones. When both chose colonial anemones, each fish occupied a separate anemone.

\section{Competition experiment}

Interspecific competition was evident in both solitary (in all 10 trials one species displaced the other, binomial probability, $\mathrm{p} \ll 0.001$ ) and colonial (in 7 of 10 trials one species displaced the other, binomial probability, $p<0.05$ ) anemone morphs. Neither species was competitively dominant in either solitary (each species displaced the other in 5 of 10 trials, binomial probability, $\mathrm{p}>0.24$ ) or colonial (Premnas biaculeatus displaced Amphiprion melanopus in 4 of 7 trials, binomial probability, $p>0.27$ ) morphs. When $P$. biaculeatus displaced $A$. melanopus, the pair occupied the solitary anemone or colonial anemones. When. A. melanopus displaced $P$. biaculeatus, the largest individual occupied the solitary anemone in 4 of 5 trials, and, in the colonial anemones, the $2 \mathrm{~A}$. melanopus individuals each occupied a separate anemone. In 3 trials the $A$. melanopus pair and a small male $P$. biaculeatus occupied the colonial anemones.

In all trials of the intraspecific competition treatments using Premnas biaculeatus, a single pair occupied the anemone(s), displacing the other pair (binomial probability, $\mathrm{p} \ll 0.001$ for both morphs). In the intraspecific competition treatment using Amphiprion melanopus (c) $2 A+2 A$

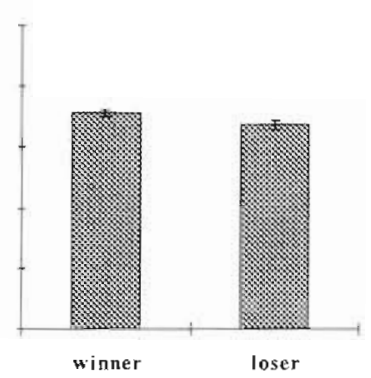

Fig. 3. Mean sizes of winners and losers for (a) interspecific treatments, in the cases where Amphiprion melanopus (A) or Premnas biaculeatus (P) won, (b) intraspecific $P$. biaculeatus females and males, and (c) intraspecific $A$. melanopus. In each case, solitary and colonial treatments were combined

and the solitary anemone morph, an individual fish (usually the largest) displaced the other 3 from the solitary anemone in 9 of 10 trials (binomial probability, p $\ll$ 0.001). In the treatment using colonial anemones, between 1 and 4 A. melanopus occupied the anemones with each fish occupying anemones singly and the largest fish occupying the largest, most centrally placed anemone (binomial probability, $p>0.11$ ).

The sizes of the largest winner and largest loser in the interspecific treatments did not differ significantly, either where Premnas biaculeatus won (paired $t$-test, $t=-1.78, p>0.11$ ) or where Amphiprion melanopus won (paired $t$-test, $t=1.01, p>0.33$, Fig. 3a). In the $P$. biaculeatus intraspecific treatments, the winning female and male were always significantly larger (paired $t$-tests, females: $t=3.12, \mathrm{p}<0.01$, males: $t=$ 3.26, $p<0.005$ ) than the displaced female and male (Fig 3b). In trials ( $N=5$ in solitary anemones, $N=4$ in colonial anemones) where the female of one pair was larger than the other female, but its mate was smaller than the male of the other pair, the largest female and largest male from the 2 pairs occupied the anemone(s). In the $A$. melanopus intraspecific treatments, the winner. was significantly larger (paired $t$-test, $t=4.42, \mathrm{p}<$ 0.001 ) than the largest of the losers (Fig. 3c).

The frequency of attacks and mean attack distance both differed significantly among the treatments (Table 1). In the interspecific interactions, there were no differences in the frequency of attacks and attack distance between trials where premnas biaculeatus won and those where Amphiprion melanopus won (P wins vs A wins, Table 1). There were significant differences in the frequency of attacks and attack distance between interspecific and intraspecific treatments (Intra vs Inter, Table 1), and between intraspecific $P$. biaculeatus and intraspecific $A$. melanopus treatments (Intra P vs Intra A, Table 1).

The intraspecific interactions between Premnas biaculeatus pairs were the most aggressive, with the highest frequency of attacks and longest attack distances (Fig. 4). In almost all the P. biaculeatus intraspecific trials, attack distance was usually equal to the tank diameter and the losing pair had to be removed as 
Table 1 Planned contrasts of differences in the frequency of attacks and attack distance between the 2 intraspecific treatments (Intra $P$ and Intra A) and the trials of interspecific treatments where Premnas biaculeatus won (P win) and those where Amphiprion melanopus won (A win). A: A. melanopus; P: P. biaculeatus. $\mathrm{p}$-values indicating statistically significant differences are given in bold

\begin{tabular}{|c|c|c|c|c|c|c|}
\hline Source of variation & $\mathrm{df}$ & MS & $F$ & $\mathrm{p}$ & Contrast & $\mathrm{p}$ \\
\hline (a) Frequency of attacks & 3 & 643.587 & 17.096 & 0.000 & $P$ win vs $A$ win & 0.358 \\
\hline Residual & 56 & 37.646 & & & Intra Pvs Intra A & 0.000 \\
\hline Total & 59 & & & & Intra vs Inter & 0.023 \\
\hline (b) Attack distance & 3 & 41154.200 & 136.658 & 0.000 & P win vs $A$ win & 0.142 \\
\hline Residual & 56 & 301.148 & & & Intra $P$ vs Intra $A$ & 0.000 \\
\hline Total & 59 & & & & Intra vs Inter & 0.000 \\
\hline
\end{tabular}

(a) attack frequency

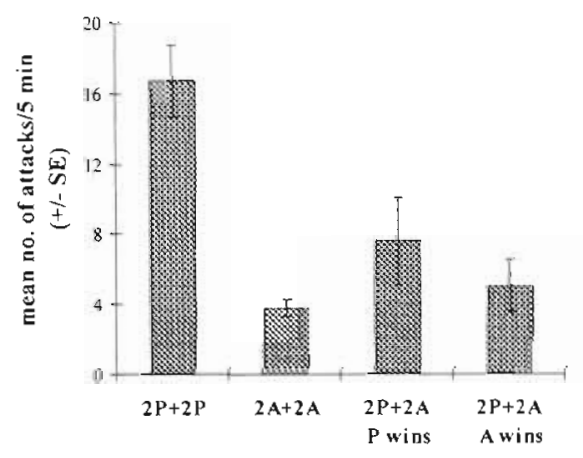

(b) attack distance

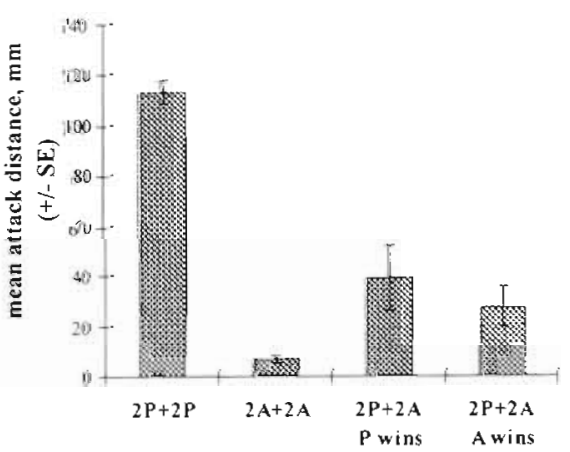

Fig. 4. Level of aggression in the 2 intraspecific treatments $(2 P+2 P$ and $2 A+2 A)$, and interspecific treatments $(2 P+2 A)$ where Premnas biaculeatus or Amphiprion melanopus won, showing (a) the mean frequency of attacks and (b) the attack distance, or the minimum distance that losing fish could approach anemones without being attacked by fish in the anemone(s). In each case, solitary and colonial treatments were combined. Treatments are denoted by the number and species of fish (P: P. biaculeatus, A: A. melanopus)

the winning pair (mainly the female) would continuously leave the anemone(s) to attack them. Fighting occurred frequently in the $P$. biaculeatus intraspecific trials. Typically, females and males only fought individuals of the same sex, and males often exhibited appeasement behaviour when chased by females. The Amphiprion melanopus intraspecific interactions were the least aggressive, with a low frequency of attacks and short attack distances (Fig. 4). The displaced fish often hovered within $5 \mathrm{~cm}$ of the anemone(s) without being attacked or chased away. A. melanopus individuals nudged each other out of anemones and smaller individuals often exhibited appeasement behaviour when chased by larger individuals. In the interspecific trials, the level of aggression was intermediate between that of the 2 intraspecific treatments.

\section{DISCUSSION}

The 2 anemonefish species, Premnas biaculeatus and Amphiprion melanopus, are highly specialised in their use of Entacmaea quadricolour as hosts, with the former using the solitary morph almost exclusively, and the latter the colonial morph. This pattern was almost identical at 2 widely separated geographic locations and, therefore, demands a general explanation. Traditional ecological theory suggests 2 potential explanations: (1) the evolution of strong habitat selection and resource partitioning due to historical evolutionary processes, including past competition (Connell 1980), and (2) the importance of interspecific competition and competitive dominance, which can lead to habitat partitioning on ecological time scales (Smith \& Tyler 1972, Robertson \& Lassig 1980). Neither of these 2 possible explanations were wholly supported by this experimental study.

Adults of Amphiprion melanopus exhibited preference for the colonial morph of Entacmaea quadricolour whereas Premnas biaculeatus exhibited no preference. $P$. biaculeatus pairs always associated closely in the tank experiments regardless of which anemone morph they chose, whereas $A$. melanopus acted individually, occupying anemones (either solitary or colonial) singly. When one A. melanopus individual occupied the solitary anemone, the other occupied the colonial ane- 
mones. Therefore, patterns of association of individuals observed in this experiment reflect patterns of association observed in the field.

Habitat preferences of juveniles were not directly investigated in this study. It is possible that settlement preferences of larval anemonefishes might influence the distribution of adults of these 2 species between Entacmaea quadricolour morphs. Settling anemonefishes are thought to locate anemones using chemical cues (Murata et al. 1986, Miyagawa 1989, Elliot 1992, Elliot et al. 1995). A recent study, involving transplantation of solitary and colonial anemones to different environments, has demonstrated that local microhabitat can influence the form of $E$. quadricolour implying that the morphs are a single species (Richardson et al. 1997). Whether or not chemical attractants vary between the 2 morphs of $E$. quadricolour and whether or not settling Premnas biaculeatus and Amphiprion melanopus use these cues to select habitats is unknown. The distribution of juveniles among anemone morphs in the field suggests habitat selection by them. Observed patterns of habitat occupation by juveniles, however, were not as extreme as the habitat partitioning evident in the adult distributions. Therefore, habitat selection by juveniles is an insufficient explanation for adult distribution patterns.

Adult anemonefishes, both heterospecifics (Hattori 1995, Elliott et al. 1995) and conspecifics (Ochi 1986, Hattori 1995, Elliott et al. 1995), can be very aggressive towards settling juveniles. This aggression may influence the settlement patterns of juveniles of each of the 2 anemonefishes on Entacmaea quadricolour morphs and their subsequent survivorship. Juveniles of either species would likely have a better chance of avoiding encounters with resident fishes in a large aggregation of colonial anemones than in a solitary one. This may explain the more frequent occurrence of juvenile Premnas biaculeatus in colonial anemones. Once they grow larger, these individuals may be displaced from the anemones by resident Amphiprion melanopus individuals and may have to locate other anemones.

This competition experiment indicated that both interspecific and intraspecific competition occurred with similar intensity. Neither species was competitively dominant in either form of anemone, each species winning roughly half the time. In intraspecific trials, the largest pair of Premnas biaculeatus always displaced the other, regardless of anemone morph. Amphiprion melanopus occupied anemones singly and, on average, more individuals co-occurred in colonial anemones. The results of the present study are not consistent with those of a previous study by Fautin (1986) in which $P$. biaculeatus was inferred to be the competitively dominant species. She conducted field experiments at Lizard Island where individuals of 1 of
3 anemonefish species, $P$. biaculeatus, $A$. melanopus, and $A$. akindynos (which also occupies $E$. quadricolour at Lizard Island), were placed in anemones occupied by either of the other 2 species and their interactions observed. She also observed interactions between a small number of individuals of the 3 species in aquaria. She concluded from these observations that a competitive hierarchy exists, $P$. biaculeatus being the competitively dominant species, and that $P$. biaculeatus and A. melanopus each prefer the form of E. quadricolour they usually occupy. Differences between our results and Fautin's may result from differences in experimental protocols. In this study, fish were matched for size as closely as possible, and, since the fish were released simultaneously into the anemones, neither pair had a 'home advantage' that could have influenced the outcome of the interaction observed here.

Since habitat preference was exhibited by only 1 of the 2 anemonefish species and no competitive dominance was apparent, other factors are required to explain patterns of distribution of these species among Entacmaea quadricolour morphs. While larval habitat selection and aduil-juveriile interactions may be important, constraints imposed on habitat use by the different social systems of the 2 anemonefish species may also be important in determining adult distributions. Amphiprion melanopus has large social groups, with up to 20 individuals in a cluster of colonial anemones. Individuals, both adults and juveniles, move among anemones in the colonial cluster but they each have an anemone (or several anemones) as their territory which they defend against other individuals in the sacial group (Ross 1978). Thus, solitary anemones may not be able to support viable social groups of this species. When $A$. melanopus were observed occupying solitary anemones in the field, they did so as a single fish, suggesting that a solitary anemone cannot support a breeding pair. As observed in the choice and competition experiments $A$. melanopus almost always occupy anemones (whether solitary or colonial) singly.

Premnas biaculeatus occur in pairs and are highly territorial and aggressive towards members of the same species, but the male and female in the pair do not defend separate territories as Amphiprion melanopus pairs do. The social structure of $P$. biaculeatus is more suited to living in solitary anemones. Colonial anemones are usually found in shallow water, on the reef crest, and pairs of $P$. biaculeatus may not be able to defend a large colonial cluster of anemones in such exposed habitats. In contrast, solitary anemones generally occur deep in holes and crevices in corals or among branching corals such as Porites cylindrica, and $P$. biaculeatus may prefer these more protected habitats. 
In conclusion, although interspecific competition was evident, neither species was clearly dominant and there were no reversals of dominance between these fish species in different morphs of Entacmaea quadricolour. Therefore, interspecific competition is not an adequate explanation for the distribution of adults of these 2 species among anemone morphs. Instead a combination of preference of Amphiprion melanopus for colonial anemones and a social preference of Premnas biaculeatus for occupying anemones in pairs is sufficient to explain much of the pattern of adult distributions among anemone morphs. Neither preference nor competitive ability is sufficient to explain the exclusive occupation of solitary anemones by $P$. biaculeatus. The cause of this pattern remains to be investigated.

Acknowledgements. This paper is based on a BSc (Honours) thesis submitted by M.S. at James Cook University. We thank the staff at the Lizard Island and Mahonia Na Dari Research Stations, for contributing to the success of this research, and to Brandt Foster for his assistance in collecting anemonefishes used in these experiments. This research was supported by the Australian Research Council, School of Marine Biology and Aquaculture, James Cook University and S. Srinivasan.

\section{LITERATURE CITED}

Allen GR (1972) The anemonefishes: their classification and biology. TFH Publ Inc, Neptune City

Anderson GRV, Ehrlich AH, Ehrlich PR, Roughgarden JD, Russel BC, Talbot FH (1981) The community structure of coral reef fishes. Am Nat 117:476-495

Armstrong RA, McGehee R (1980) Competitive exclusion. Am Nat 115:151-170

Caley MJ, Carr MH, Hixon MA, Hughes TP, Jones GP, Menge BA (1996) Recuitment and the local dynamics of open marine populations. Annu Rev Ecol Syst 27:477-500

Connell JH (1980) Diversity and coevolution of competitors, or the ghost of competition past. Oikos 35:131-138

Connell JH (1983) On the prevalence and relative importance of interspecific competition: evidence from field experiments. Am Nat 122:661-696

Doherty PJ (1982) Some effects of density on the juveniles of two species of tropical, territorial damselfish. J Exp Mar Biol Ecol 65:249-261

Doherty PJ, Williams DMB (1988) The replenishment of coral reef fish populations. Oceanogr Mar Biol Annu Rev 26: $487-551$

Dunn DF (1981) The clownfish sea anemones. Trans Am Philos Soc 71:1-115

Ebersole JP (1985) Niche separation of two damselfish species by aggression and differential microhabitat utilisation. Ecology 66:14-20

Eckert GJ (1985) Settlement of coral reef fishes to different natural substrata and at different depths. Proc 5th Int Coral Reef Congr 5:385-390

Elliot JK (1992) Factors influencing the distribution, abundance and host specificity patterns of anemonefishes. PhD thesis, Florida State University

Elliot JK, Elliot JM, Mariscal RN (1995) Host selection, location, and association behaviours of anemonefishes in field settlement experiments. Mar Biol 122:377-389
Fautin DG (1985) Competition by anemonefishes for host actinians. Proc 5th Int Coral Reef Congr 5:373-377

Fautin DG (1986) Why do anemonefishes inhabit only some host actinians? Environ Biol Fish 15:171-180

Fautin DG (1992) Anemonefish recruitment: the roles of order and chance. Symbiosis 14:143-160

Fautin DG, Allen GR (1992) Field guide to anemonefishes and their host sea anemones. Western Australian Museum Publ, Perth

Hattori A (1995) Coexistence of two anemonefishes, Amphiprion clarkii and Amphiprion perideraion, which utilize the same host sea anemone. Environ Biol Fish 42:34.5-353

Jones GP (1988) Experimental evaluation of the effects of habitat structure and competitive interactions on the juveniles of two coral reef fishes. J Exp Mar Biol Ecol 123: $115-126$

Jones GP (1991) Post-recruitment processes in the ecology of coral reef fish populations: a multifactorial perspective. In: Sale PF (ed) The ecology of fishes on coral reefs. Academic Press, San Diego, p 294-330

MacArthur RH, Levins R (1964) Competition, habitat selection and character displacement in a patchy environment. Proc Nat Acad Sci 51:1207-1210

MacArthur RH, Levins R (1967) The limiting similarity, convergence, and divergence of coexisting species. Am Nat 101:377-385

Mariscal RN (1970) The nature of the symbiosis between Indo-Pacific anemone fishes and sea anemones. Mar Biol $6.58-65$

Mariscal RN (1972) Behaviour of symbiotic fishes and sea anemones. In: Winn HE, Olla BL (eds) Behaviour of marine animals, Vol 2, 1st edn. Plenum Press, New York, p 327-361

Miyagawa K (1989) Experimental analysis of the symbiosis between anemonefish and sea anemones. Ethology 80: $19-46$

Moyer JT, Bell LJ (1976) Reproductive behaviour of the anemonefish Amphiprion clarkii at Miyake-Jima, Japan Jpn J Ichthyol 23:23-32

Murata M, Miyagawa-Kohshima K, Nakanishi K, Naya Y (1986) Characterization of compounds that induce symbiosis between sea anemone and anemone fish. Science 234 : $585-587$

Ochi H (1986) Growth of the anemonefish Amphiprion clarkii in temperate waters, with special reference to the influence of settling time on the growth of 0 -year olds. Mar Biol 92:223-229

Ohman MC, Munday PL, Jones GP, Caley MJ (1998) Settlement strategies and distribution patterns of coral-reef fishes. J Exp Mar Biol Ecol 225:219-238

Richardson DL, Hariott VJ, Harrison PL (1997) Distribution and abundance of giant sea anemones (Actinaria) in subtropical eastern Australian waters. Mar Freshw Res 48: $59-66$

Roberts CM (1985) Resource sharing in territorial herbivorous reef fishes. Proc 5th Int Coral Reef Congr 4:17-22

Roberts CM (1987) Experimental analysis of resource sharing between herbivorous damselfish and blennies on the Great Barrier Reef. J Exp Mar Biol Ecol 111:61-75

Robertson DR (1984) Cohabitation of competing territorial damselfishes on a Caribbean coral reef. Ecology 65: $1121-1135$

Robertson DR (1996) Interspecific competition controls abundance and habitat use of territorial Caribbean damselfishes. Ecology 77:885-889

Robertson DR, Gaines S (1986) Interference competition structures habitat in a local assemblage of coral reef surgeonfishes. Ecology 67:1372-1383 
Robertson DR, Lassig B (1980) Spatial distribution patterns and coexistence of a group of territorial damselfishes from the Great Barrier Reef. Bull Mar Sci 30:197-203

Ross RM (1978) Territorial behaviour and ecology of the anemonefish Amphiprion melanopus on Guam. Z Tierpsychol 36:71-83

Sale PF (1978) Coexistence of coral reef fishes-a lottery for living space. Environ Biol Fish 3:85-102

Sale PF (1980) The ecology of fishes on coral reefs. Oceanogr Mar Biol Annu Rev 18:367-421

Sale PF, Williams DM (1982) Community structure of coral reef fishes: are the patterns more than those expected by chance? Am Nat 120:121-127

Sale PF, Doherty PJ, Douglas WA (1980) Juvenile recruitment strategies and the coexistence of territorial pomacentrid fishes. Bull Mar Sci 30:147-158

Sale PF, Douglas WA, Doherty PJ (1984) Choice of microhabitats by coral reef fishes at settlement. Coral Reefs 3 : 91-99

Editorial responsibility: Otto Kinne (Editor),

Oldendorf/Lune, Germany
Schoener TW (1983) Field experiments on interspecific competition. Am Nat 122:240-285

Schoener TW (1985) Some comments on Comell's and my reviews of field experiments on interspecific competition. Am Nat 125:730-740

Smith CL (1978) Coral reef fish communities: a compromise view. Environ Biol Fish 3:109-128

Smith CL, Tyler JC (1972) Space resource sharing in a coral reef fish community. Bull Nat Hist Mus Los Angeles County 14:125-170

Victor BC (1986) Larval settlement and juvenile mortality in a recruitment-Jimited coral reef fish population. Ecol Monogr 56:145-160

Waldner RE, Robertson DR (1980) Patterns of habitat partitioning by eight species of territorial Caribbean damselfishes (Pisces: Pomacentridae). Bull Mar Sci 30:171-186

Williams DMB (1980) Dynamics of the pomacentrid community on small patch reefs in One Tree Lagoon (Great Barrier Reefj. Bull Mar Sci 30:159-170

Submitted: January 8, 1999; Accepted: April 30, 1999 Proofs received from author(s): August 17, 1999 